\title{
Rapid and Direct Detection of Clostridium chauvoei by PCR of the 16S-23S rDNA Spacer Region and Partial 23S rDNA Sequences
}

\author{
Yoshimasa SASAKI ${ }^{1)}$, Kinya YAMAMOTO' ${ }^{1)}$, Akemi KOJIMA ${ }^{1)}$, Yukie TETSUKA ${ }^{2)}$, Mari NORIMATSU ${ }^{3)}$ and \\ Yutaka TAMURA ${ }^{1)}$ \\ ${ }^{1)}$ National Veterinary Assay Laboratory, 1-15-1 Tokura, Kokubunji, Tokyo 185-8511, ${ }^{2}$ Tochigi Pre. Kenhoku Animal Hygiene Center, \\ 12-14 Midori-machi, Nishinasuno-cho, Nasu-gun, Tochigi 329-2713, Japan and ${ }^{3)}$ Institute for Animal Health, Compton, Newbury, \\ Berkshire, RG207NN, UK
}

(Received 24 May 2000/Accepted 18 August 2000)

\begin{abstract}
Clostridium chauvoei causes blackleg, which is difficult to distinguish from the causative clostridia of malignant edema. Therefore, a single-step PCR system was developed for specific detection of $C$. chauvoei DNA using primers derived from the 16S-23S rDNA spacer region and partial $23 \mathrm{~S}$ rDNA sequences. The specificity of the single-step PCR system was demonstrated by testing 37 strains of clostridia and 3 strains of other genera. A 509 bp PCR product, which is a $C$. chauvoei-specific PCR product, could be amplified from all of the C. chauvoei strains tested, but not from the other strains. Moreover, this single-step PCR system specifically detected C. chauvoei DNA in samples of muscle from mice $24 \mathrm{hr}$ after inoculation with 100 spores of $C$. chauvoei, and in clinical materials from a cow affected with blackleg. These results suggest that our single-step PCR system may be useful for direct detection of $C$. chauvoei in culture and in clinical materials from animals affected with blackleg. KEY wORDS: Clostridium chauvoei, PCR, 16S-23S rDNA spacer region.
\end{abstract}

Clostridium chauvoei is an endospore-forming gram-positive bacterium, which causes blackleg, a fatal disease of cattle, sheep, and other ruminants associated with sporecontaminated soil. Blackleg needs to be distinguished from other severe diseases with similar symptoms, such as 'malignant edema' and anthrax caused by Clostridium septicum, Clostridium novyi, Clostridium perfringens, Clostridium sordellii or Bacillus anthracis. Typically, the diagnosis of blackleg depends on observation of clinical symptoms, followed by isolation and identification of the organism by immunological methods, such as immunofluorescence staining [10]. However, these diagnostic methods are time consuming and laborious.

Nucleic acid amplification of a specific target region of the bacterial genome by the polymerase chain reaction (PCR) is becoming widely used for detection and diagnostic purposes $[18,19]$. The ability of PCR to amplify DNA specifically from low numbers of bacteria, as well as its simplicity, rapidity and reproducibility, offers advantages over conventional methods for identification. Kuhnert et al. [14] reported a PCR system for distinguishing C. chauvoei from C. septicum by using specific oligonucleotide primers for the $16 \mathrm{~S}$ rRNA gene. This procedure is very effective in distinguishing $C$. chauvoei from $C$. septicum; however it requires restriction enzyme digestion of the PCR products for definitive identification of the organism, because the existence of only small differences in the 16S rRNA gene sequences, results in the primers amplifying the 16S rRNA genes of both bacteria. PCR amplification of the 16S-23S rDNA spacer region has been suggested as a target for a universal bacterial identification and typing system [3, 9, 12]. Recently, it has been reported that species-specific primers to Actinobacillus seminis were developed from the sequence of the $16 \mathrm{~S}-23 \mathrm{~S}$ rDNA spacer region of $\mathrm{rrnB}$ for the identification and detection of A. seminis by PCR [1].

In the present study, we determined three distinct $16 \mathrm{~S}-23 \mathrm{~S}$ rDNA spacer regions and the partial 23S rDNA sequences of C. chauvoei and designed C. chauvoei-specific primers for the detection of $C$. chauvoei. To assess its applicability as a rapid and reliable diagnostic method for clinical blackleg in ruminants, we evaluated our single-step PCR system using specimens from mice experimentally infected with $C$. chauvoei and clinical materials from a cow affected with blackleg.

\section{MATERIALS AND METHODS}

Bacterial strains: Bacterial strains used are listed in Table 1 .

DNA preparation: To isolate chromosomal DNA from bacteria, cells in $1 \mathrm{~m} l$ of a late logarithmic phase culture were pelleted by centrifugation and used as the source of chromosomal DNA. To isolate the DNA samples from mice and a cow, approximately $50 \mathrm{mg}$ of each of the vital organs was homogenated and resuspended in $3 \mathrm{ml}$ of phosphate buffered saline $(\mathrm{PBS})$, then centrifuged at $800 \times \mathrm{g}$ for $10 \mathrm{~min}$. The supernatant was centrifuged at $10,000 \times \mathrm{g}$ for $10 \mathrm{~min}$. The pellets were washed once with in $1.5 \mathrm{ml}$ of PBS, and resuspended in $150 \mu \mathrm{l}$ of sucrose-TES $(25 \%$ [w/v] sucrose, $10 \mathrm{mM}$ Tris- $\mathrm{HCl}, 1 \mathrm{mM}$ EDTA, $150 \mathrm{mM} \mathrm{NaCl}$ ) containing $4 \mathrm{mg} / \mathrm{ml}$ of lysozyme. The DNA extraction and purification was performed according to the methods of Takeuchi et al. [17].

DNA amplification and gel electrophoresis: PCR was performed in a reaction volume of $100 \mu l$ containing $1 \times$ PCR buffer $\left(\mathrm{Mg}^{2+}\right.$ free $), 2.5 \mathrm{mM} \mathrm{MgCl} 2,0.2 \mathrm{mM}$ dNTP mixture, 2.5 units of LA Taq DNA polymerase (TaKaRa LA Taq kit; TaKaRa Shuzo Co., Ltd., Kyoto, Japan), 10 pmol of each 
Table.1 The list of bacterial strains and results of PCR

\begin{tabular}{|c|c|c|}
\hline Bacterial strains & Source & PCR results ${ }^{\mathrm{d})}$ \\
\hline \multicolumn{3}{|l|}{ C. chauvoei } \\
\hline ATCC10092a) & Type strain & $+(1)$ \\
\hline ATCC 11956 & & $+(2)$ \\
\hline ATCC11958 & & $+(3)$ \\
\hline ATCC11957 & & $+(4)$ \\
\hline ATCC19399 & & $+(5)$ \\
\hline Okinawa & Japanese vaccine strain & $+(6)$ \\
\hline Chousen & Clinical isolated & + \\
\hline Souya & Clinical isolated & + \\
\hline Tochigi & Clinical isolated & + \\
\hline Iwate & Clinical isolated & + \\
\hline Ouita & Clinical isolated & + \\
\hline Yamanashi & Clinical isolated & + \\
\hline S4269A & Clinical isolated & + \\
\hline $\mathrm{C} 6 \mathrm{H}$ & Clinical isolated & + \\
\hline \multicolumn{3}{|l|}{ C. septicum } \\
\hline JCM8144 ${ }^{\text {b) }}$ & Type strain & $-(7)$ \\
\hline NCTC551 ${ }^{\mathrm{c})}$ & & $-(8)$ \\
\hline NCTC286 & & $-(9)$ \\
\hline NCTC282 & & $-(10)$ \\
\hline NCTC504 & & - \\
\hline 44 & Japanese vaccine strain & - \\
\hline \multicolumn{3}{|l|}{ C. novyi } \\
\hline JCM1406 & Type strain & $-(11)$ \\
\hline ATCC25758 & Type B & - \\
\hline CN1025 & Japanese vaccine strain & - \\
\hline ATCC19402 & Type A & - \\
\hline \multicolumn{3}{|l|}{ C. perfringens } \\
\hline JCM1290 & Type strain & $-(12)$ \\
\hline PB6K & Type A & - \\
\hline \multicolumn{3}{|l|}{ C. sordelli } \\
\hline JCM3814 & Type strain & $-13)$ \\
\hline CL-2 & Clinical isolated & - \\
\hline \multicolumn{3}{|l|}{ C. haemolyticum } \\
\hline ATCC 9650 & Type strain & - \\
\hline ATCC9652 & & - \\
\hline \multicolumn{3}{|l|}{ C. carnis } \\
\hline JCM1393 & Type strain & $-(15)$ \\
\hline \multicolumn{3}{|l|}{ C. difficile } \\
\hline JCM1296 & Type strain & - \\
\hline \multicolumn{3}{|l|}{ C. tetani } \\
\hline $\mathrm{T} 3$ & Clinical isolate & - \\
\hline harvard & Clinical isolate & - \\
\hline \multicolumn{3}{|l|}{ C. sporogenes } \\
\hline 80011 & Clinical isolated & - \\
\hline \multicolumn{3}{|l|}{ C. acetobutylicum } \\
\hline JCM1419 & Type strain & - \\
\hline \multicolumn{3}{|l|}{ C. butylicum } \\
\hline Miyairii & & - \\
\hline \multicolumn{3}{|l|}{ B. anthracis } \\
\hline $17 \mathrm{JB}$ & Japanese challenge strain & $-(14)$ \\
\hline $34 \mathrm{~F}_{2}$ & Japanese vaccine strain & - \\
\hline \multicolumn{3}{|l|}{ B. subtilis } \\
\hline ATCC6633 & & - \\
\hline
\end{tabular}

a) ATCC, American Type Culture Collection, USA.

b) JCM, Japan Collection of Microorganisms, Japan.

c) NCTC, National Collection of Type Culture, UK.

d) ( ), Lane no. in Fig. 2.

primer, and $1 \mu l$ of each template DNA solution. The primers are shown in Table 2 and Fig. 1C. Cycle conditions were an initial 5 min denaturation at $94^{\circ} \mathrm{C}$, followed by 30 cycles, each consisting of $1 \mathrm{~min}$ denaturation at $94^{\circ} \mathrm{C}, 1 \mathrm{~min}$ annealing at $54^{\circ} \mathrm{C}$, and $1.5 \mathrm{~min}$ extension at $72^{\circ} \mathrm{C}$. These 30 cycles were followed by $7 \mathrm{~min}$ extension at $72^{\circ} \mathrm{C}$. The amplified products were separated by electrophoresis in $2.0 \%(\mathrm{w} / \mathrm{v})$ agarose gels and stained with ethidium bromide. The identity of the PCR products was confirmed by cleavage with Hind III (TaKaRa Shuzo Co., Ltd., Kyoto, Japan).

Sequencing of the PCR-amplified 16S-23S rDNA spacer region genes and partial $23 S$ rRNA gene: The amplified products of $C$. chauvoei type strain ATCC $10092^{\mathrm{T}}$ ( $\mathrm{T}=$ Type strain) were recovered from an agarose gel and were cloned into the pCR II plasmid vector using the TA cloning system version 2.2 (Invitrogen Corp., San Diego, Calif.) according to the manufacture's instructions. Automated DNA sequencing of samples of purified plasmid DNA were performed on a DNA sequencer (model 373A, PE Biosystems, Co., Ltd., U.S.A.). The $r r n A$ sequences of the other strains and partial $23 \mathrm{~S}$ rDNA gene sequence of the type strain were determined by direct sequencing. All the sequences were confirmed by sequencing both strands. The sequences have been registered in the DDBJ database under the accession numbers: AB040539 (23S rRNA gene), AB040540 (rrnA), AB040541 ( $r r n B)$, and AB040542 ( $r r n C)$.

Detection of $C$. chauvoei DNA in mice experimentally infected with $C$. chauvoei and in a cow affected with blackleg: Eight-week-old female ddY mice were supplied by SLC, Co., Ltd. (Shizuoka, Japan). Three mice were inoculated in the middle of the right thigh with 100 spores of ATCC10092 in $0.25 \mathrm{ml}$ of $6 \%(\mathrm{w} / \mathrm{v})$ calcium chloride solution. Mice were sacrificed to obtain samples at $24 \mathrm{hr}$ after inoculation. Clinical materials (muscle, blood and liver) were collected from a cow that died in an outbreak of blackleg in Tochigi Prefecture, Japan. The cow was diagnosed as having blackleg by clinical and pathological findings and $C$. chauvoei were detected in the clinical materials by the immunofluorescence technique. Samples from the cow affected with blackleg were cultured on CLA agar [2] supplemented with 5\% (v/v) defibrinated sheep blood (CLA medium), and in CLB broth [2] under an anaerobic condition. Colonies forming a hemolytic zone were picked, and then cultured three times in a new CLA medium. The isolated cells were used as the source of chromosomal DNA. Muscle samples from a normal mouse and a normal cow were used as negative controls. DNA isolation and PCR were performed as described above.

\section{RESULTS}

16S-23S rDNA spacer regions of $C$. chauvoei: The PCR was performed with total DNA from 3 strains of $C$. chauvoei including type strain ATCC10092 ${ }^{\mathrm{T}}$ using the primers $16-23 \mathrm{~S}$ and 16-23AS. As shown in Fig. 1A, all the C. chauvoei strains had at least three sizes of PCR products. The bands of $286 \mathrm{bp}, 363 \mathrm{bp}$ and 441-bp were designated as $r r n A, r r n B$ and $r r n C$, respectively. The PCR products of type strain ATCC10092 ${ }^{\mathrm{T}}$ were sequenced (Fig. 1B). The three PCR products share common sequences, however DNA 


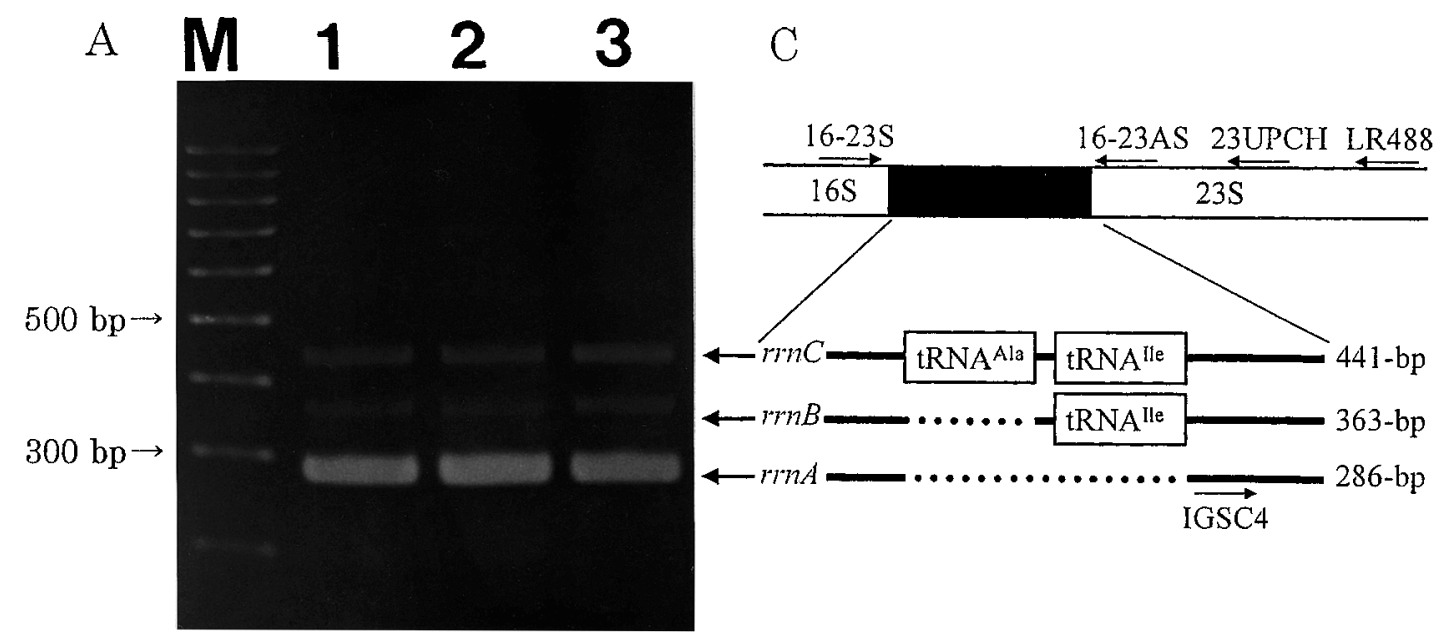

$\mathrm{B}$

\begin{tabular}{|c|c|c|c|c|c|c|}
\hline $\operatorname{rrnc}$ & 1 & GAGAACCTGC & $\begin{array}{r}20 \\
\text { GGCTGGATCA }\end{array}$ & $\begin{array}{r}30 \\
\text { CCTCCTTTCT }\end{array}$ & $\begin{array}{r}40 \\
\text { ATGGAGAAAT }\end{array}$ & $\begin{array}{r}50 \\
\text { ATAGTTAACA }\end{array}$ \\
\hline$\overline{r r n B}$ & 1 & GAGAACCTGC & GGCTGGATCA & CCTCCTTTCT & ATGGAGAAAT & CTAGTTAACA \\
\hline rrnA & 1 & GAGAACCTGC & GGCTGGATCA & CCTCCTTTCT & ATGGAGAAAT & CTAGTTAACA \\
\hline & & 60 & 70 & 80 & 90 & 100 \\
\hline$r \operatorname{rnc}$ & 51 & AGATGATTAA & CTAGTATATT & TCAAAAGAAG & CGTTATCTTA & ACTTCTGTTC \\
\hline $\mathrm{rrnB}$ & 51 & AGATGATTAA & CTAGTATATT & TCAAAAGAAA & CGTTATCTTA & ACTTCTGTTC \\
\hline rrnA & 51 & AGATGATTAA & CTAGTATATT & TCAAAAGAAG & AGTTATCTTA & ACTTCTGTTC \\
\hline & & 110 & 120 & 130 & 140 & 150 \\
\hline $\mathrm{rrnc}$ & 101 & AATTTTGAGG & GATCTACCTC & AAAACATGTG & GGGGTATAGC & TCAGTTGGGA \\
\hline $\operatorname{crnB}$ & 101 & AATTTTGAGG & GATTTTTCCT & TCAAGAGTAT & --------- & --------- \\
\hline $\operatorname{rrnA}$ & 101 & AATTTTGAAG & GACCAAAATC & CTTCAAAATT & $\cdots+\cdots-\cdots$ & --------- \\
\hline$n \cap C$ & 151 & $\begin{array}{r}160 \\
\text { GAGCACTTGC }\end{array}$ & $\begin{array}{r}170 \\
\text { CTTGCACGCA }\end{array}$ & $\begin{array}{r}180 \\
\text { AGGGGTCAAG }\end{array}$ & $\begin{array}{r}190 \\
\text { AGTTCGATC }\end{array}$ & $\begin{array}{r}200 \\
\text { TCTTTATCTC }\end{array}$ \\
\hline $\operatorname{rrnB}$ & 151 & $\ldots-\ldots$. & -------- & 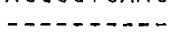 & 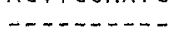 & $--\infty-0---$ \\
\hline $\mathrm{rrnA}$ & 151 & -------- & --------- & $---n-\ldots$ & $\ldots \ldots \ldots$ & $\ldots \ldots-\ldots$ \\
\hline & & 210 & 220 & 230 & 240 & 250 \\
\hline rrnc & 201 & CACCACATGG & GTCTATAGCT & CAGCTGGTTA & GAGCGCACGC & CTGATAAGCG \\
\hline rrnB & 201 & $\cdots-\cdots-G G$ & GTCTATAGCT & CAGCTGGTTA & GAGCGCACGC & CTGATAAGCG \\
\hline$r r n A$ & 201 & --------- & ---------- & --------- & -------- & $----m---\cdots$ \\
\hline & & 260 & 270 & 280 & 290 & 300 \\
\hline $\mathrm{rrnc}$ & 251 & TGAGGTCGAT & GGTTCGAGTC & CATTTAGACC & CACCATTGTT & CTTTGAAAAT \\
\hline$r \operatorname{rns}$ & 251 & TGAGGTCGAT & GGTTCGAGTC & CATTTAGACC & CACCATTGTT & CTTTGAAAAT \\
\hline $\operatorname{rrnA}$ & 251 & $--\cdots-\cdots+\cdots$ & $\ldots \ldots \ldots+\cdots$ & -------- & ---- TTGTT & CTTTGAAAAT \\
\hline & & 310 & 320 & 330 & 340 & 350 \\
\hline $\mathrm{renc}$ & 301 & TGCACATGAA & TTAAAACAAC & TTTATTAACA & AATGTTAATT & GAGAAGTGAC \\
\hline $\operatorname{rrnB}$ & 301 & TGCACATGAA & TTAAAACAAC & TTTATTAACA & AATGTTAATT & GA GAAGTGAC \\
\hline$r r \cap A$ & 301 & TGCACATGAA & TTAAAACAAC & TTTATTAACA & AATGTTAATT & GAGAAGTGAC \\
\hline & & 360 & 370 & 380 & 390 & 400 \\
\hline renc & 351 & AACAAGCCAA & GAAAAATATT & CTTTGTGATA & TAAATTGACT & CTTTGTAAAA \\
\hline $\operatorname{CPnB}$ & 351 & AACAAGCCAA & GAAAAATATT & CTTTGTGATA & TAAATTGACT & CTTTGTAAAA \\
\hline $\operatorname{rnnA}$ & 351 & $\triangle A C A A G C C A A$ & GAAAAATATT & CTTTGTGATA & TAAATTGACT & CTTTGTAAAA \\
\hline & & 410 & 420 & 430 & 440 & 450 \\
\hline renc & 401 & AGAGAACCGT & AAAGGTCAAG & CTACAAAGGG & CGCATGGTGA & $A \ldots \ldots$ \\
\hline rrnB & 401 & AGAGAACCGT & AAAGGTCAAG & CTACAAAGGG & CGCATGGTGA & A....... \\
\hline $\operatorname{rnnA}$ & 401 & $A G A G A A C C G T$ & AAAGGTCAAG & CTACAAAGGG & CGCATGGTGA & $A \ldots \ldots$ \\
\hline
\end{tabular}

Fig. 1. (A) 16S-23S rDNA spacer region patterns of C. chauvoei strains. PCR was done using the primers 16-23S and 16-23AS. Lane M: molecular size markers (100 bp DNA ladder), lane 1: ATCC10092 ${ }^{\mathrm{T}}$, lane 2: ATCC11958, lane 3: ATCC11956. (B) Sequences of three spacer regions. 1-30, 16S rDNA partial sequence; 131-206, tRNA ${ }^{\text {Ala }}$ sequence; 209-285, tRNA ${ }^{\text {Ile }}$ sequence; 413-441, 23S rDNA partial sequence. (C) Structure of the 16S-23S rDNA spacer regions of $C$. chauvoei. $\cdots \cdots$, Deleted region. $\boldsymbol{\square}, 16 \mathrm{~S}-23 \mathrm{~S}$ rDNA spacer region. 
Table 2. Primers used for amplification and/or sequencing

\begin{tabular}{llll}
\hline Primer & Sequence & Region & Position \\
\hline 16-23S & 5'GAGAACCTGCGGCTGGATC 3' & $16 \mathrm{~S}$ & $1381-1499^{\text {a) }}$ \\
16-23AS & 5'TTCACCATGCGCCCTTTGTAG 3' & $23 \mathrm{~S}$ & $28-8^{\text {b) }}$ \\
LR488 & 5'CCTTTCCCTCACGGTACTG 3' & $23 \mathrm{~S}$ & $520-502^{\text {c) }}$ \\
IGSC4 & 5'GAATTAAAACAACTTTATTAACAAATG 3' & $16 \mathrm{~S}-23 \mathrm{~S}$ rDNA spacer region & $308-334^{\text {d) }}$ \\
23UPCH & 5'GGATCAGAACTCTAAACCTTTCT 3' & $23 \mathrm{~S}$ & $403-381^{\text {e) }}$ \\
\hline
\end{tabular}

Positions according to: a) the $16 \mathrm{~S}$ rDNA sequence from $C$. chauvoei (Genbank accession no. U51843), b) the $23 \mathrm{~S}$ rDNA sequence from C. perfringens (Genbank accession no.M69264), c) the primer was reported by Gürtler [7], d) the aligned spacer sequence for C. chauvoei (Fig. 1B), e) the $23 \mathrm{~S}$ rDNA sequence from C. chauvoei (AB040539)

sequences with 77 and 155 nucleotides were inserted between the common sequences of $r r n B$ and $r r n C$, respectively (Fig. 1C). The $r r n C$ contained nucleotide sequences of alanine tRNA (tRNA ${ }^{\mathrm{Ala}}$ ) and isoleucine tRNA (tRNA ${ }^{\text {Ila }}$ ) between nucleotide positions 131 and 206, and between nucleotide positions 209 and 285 . The $r r n B$ had a tRNA ${ }^{\text {Ila }}$ gene between nucleotide positions 209 and 285, respectively. The tRNA ${ }^{\text {Ala }}$ and tRNA ${ }^{\text {Ila }}$ sequences show $79 \%$ and $95 \%$ identity with the those of the related gram-positive bacteria Staphylococcus aureus (Genbank accession no. U11781), respectively. The $r r n A$ had no tRNA genes. In short, $r r n A$ is a fundamental 16S-23S rDNA spacer region in $C$. chauvoei, and $r r n B$ or $r r n C$ was inserted with one or two tRNA genes into this fundamental region, i.e. the $r r n A$ (Fig. 1C). In order to confirm that the $r r n A$ sequence is conserved in $C$. chauvoei strains, the $r r n A$ sequences of five other strains (Okinawa, ATCC11958, ATCC11956, Souya and Chousen) were also sequenced, and they were completely identical with the $r r n A$ sequence of ATCC $10092^{\mathrm{T}}$ (data not shown). This result revealed that $C$. chauvoei-specific primers could be designed from the $r r n A$ sequence.

Design of C. chauvoei-specific primers: The sequences of the $16 \mathrm{~S}-23 \mathrm{~S}$ rDNA spacer regions of $C$. chauvoei were found partially conserved in many bacteria, including clostridia, according to the database (data not shown). The similarity was confined mainly to the $16 \mathrm{~S}$ and 5 ' end of $23 \mathrm{~S}$ rRNA genes and the tRNA gene. C. chauvoei-specific sequences of the $16 \mathrm{~S}-23 \mathrm{~S}$ rDNA spacer region genes were too narrow as a target for a single-step PCR system. Therefore, in order to establish C. chauvoei-specific primers for a single-step PCR system, the partial 23S rDNA sequence was determined with total DNA from ATCC $10092^{\mathrm{T}}$ using the primers $16-23 \mathrm{~S}$ and LR488. Two sequences, IGSC4 and 23UPCH, were chosen as specific primers (Table 2). The IGSC4 was designed from the sequences of the $16 \mathrm{~S}-23 \mathrm{~S}$ rDNA spacer regions, and 23UPCH was designed from the partial 23S rDNA sequence (Fig. 1). The size of the PCR product predicted with these primers was $509 \mathrm{bp}$. The PCR product from total DNA of ATCC $10092^{\mathrm{T}}$ was sequenced and was identified as the target sequence (data not shown). To assess its specificity, our single-step PCR system was performed with total DNA from 37 strains of clostridia and 3 strains of other genera. All of the 14 C. chauvoei strains had a 509 bp PCR product, which was not amplified from the other bacteria tested (Fig. 2A and Table 1). In order to confirm that the PCR products were the target sequences, these PCR products were digested with the restriction enzyme Hind III. As shown in Fig. 2B, two bands of the expected lengths (330 bp and $179 \mathrm{bp}$ ) were recognized.

Detection of C. chauvoei DNA in mice experimentally infected with $C$. chauvoei and in a cow affected with blackleg: To confirm the applicability of the single-step PCR system using primers IGSC4 and $23 \mathrm{UPCH}$, for routine diagnosis of blackleg disease, we examined samples from mice infected with $C$. chauvoei (Fig. 3A). Mice were sacrificed at $24 \mathrm{hr}$ after inoculation with 100 spores of ATCC10092 ${ }^{\mathrm{T}}$. Samples of affected muscle were collected from three mice infected with $C$. chauvoei. All of the samples from the infected mice yielded the $509 \mathrm{bp} \mathrm{PCR} \mathrm{product,}$ however a sample from a negative control mouse did not (Fig 3A). The single-step PCR system described above was also applied to samples from a cow affected with blackleg (Fig. 3B). Although a sample from the liver had a faint band of 509 bp PCR product, samples from the muscle and blood had strong bands of $509 \mathrm{bp}$ PCR product. The isolate from the liver named Tochigi also had a band of $509 \mathrm{bp}$ PCR product. A sample from a negative control cow did not have the PCR product.

\section{DISSCUSSION}

For detection of human and animal pathogens by PCR, most studies have targeted either species-specific genes, such as the toxin genes of $C$. perfringens $[4,11,21]$, the alphatoxin gene of $C$. septicum [17] and the urease subunit gene of Helicobacter pylori [5]. However there are no reports of the gene sequences of $C$. chauvoei, except for the 16S rRNA gene sequence. In general, it is difficult to identify speciesspecific genes. On the other hand, the rRNA genes are essential for the survival of all organisms and are highly conserved in the bacterial and other kingdoms. It is easy to determine the 16S-23S rDNA spacer region sequences using common primers designed for the highly conserved regions of the $16 \mathrm{~S}$ rRNA gene and the 23S rRNA gene sequences. Therefore, we determined the $16 \mathrm{~S}-23 \mathrm{~S}$ rDNA spacer region sequences of $C$. chauvoei. We clarified that there are at least three rRNA operons in C. chauvoei (Fig. 1). The number of rRNA 

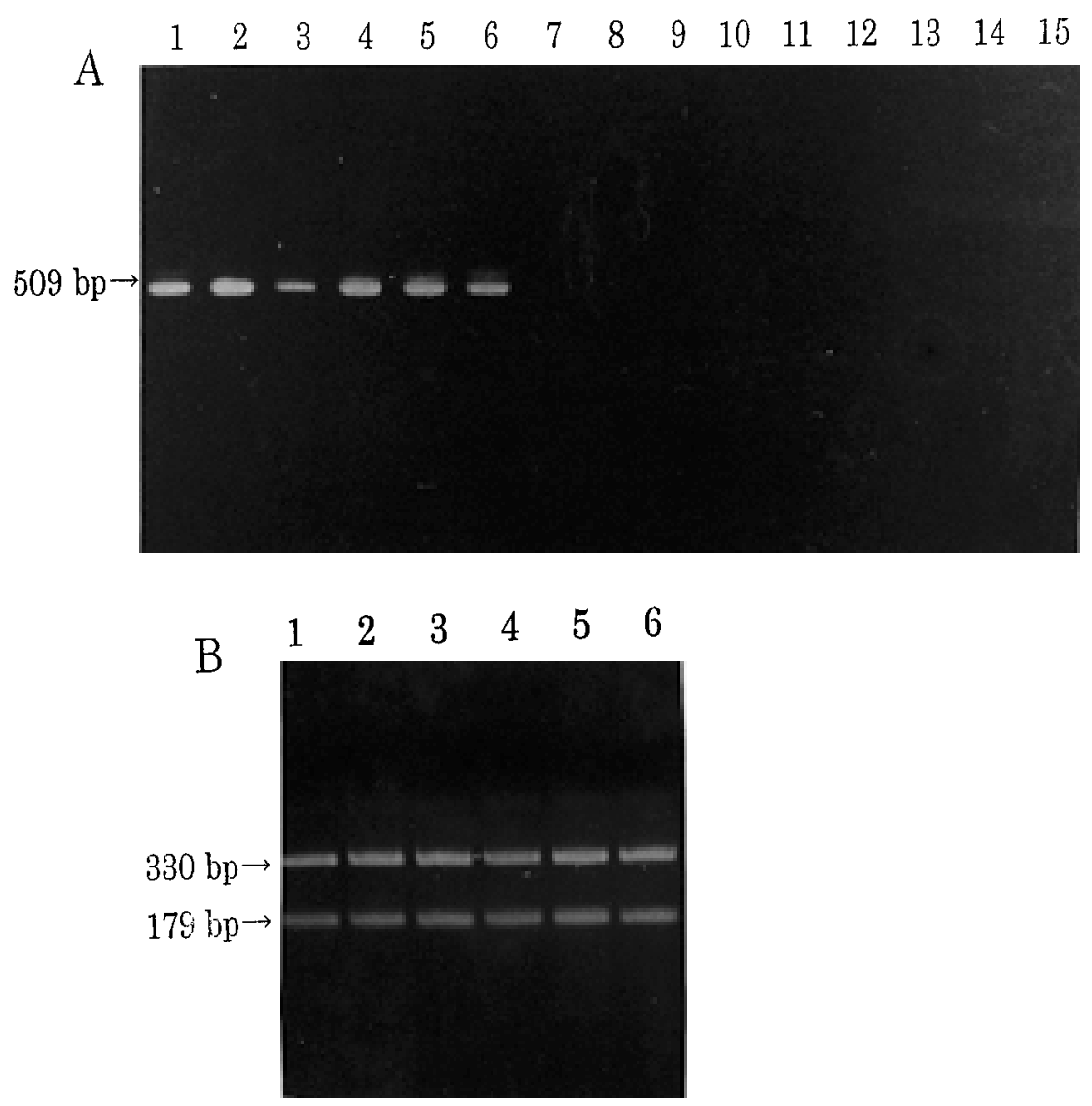

Fig. 2. (A) PCR amplification of a $509 \mathrm{bp}$ fragment from total DNA purified from cultures. Lanes 1-6: C. chauvoei strains, lanes 7-10: C. septicum strains, lane 11: C. novyi, lane 12: $C$. perfringens, lane 13: C. sordellii, lane 14: B. anthracis, lane 15: C. carnis. PCR was done with the $C$. chauvoei specific primers IGSC4 and 23UPCH. (B) Hind III-digestion of the PCR products. Lane numbers correspond to organisms as labeled in the farright column of Table 1.

operons has been completely determined in some eubacteria by Southern hybridization or PCR of the rRNA genes. For example, Escherichia coli has seven operons [15], S. aureus has 9 operons [8], C. perfringens [6] and C. difficile have 10 rRNA operons [7]. Therefore, it is possible for $C$. chauvoei to have more than three operons. We designed PCR primers specific to the region of the $16 \mathrm{~S}-23 \mathrm{~S}$ rDNA spacer region and 23S rDNA sequences of C.chauvoei. Our single-step PCR system was confirmed as distinguishing $C$. chauvoei from the causative microorganisms of 'malignant edema' and anthrax, such as C. septicum, C. novyi, C. perfringens, $C$. sordellii and $B$. anthracis without restriction digestion of the PCR products (Table 1 and Fig. 2). C. chauvoei is especially difficult to distinguish from $C$. septicum. It has been reported that $C$. chauvoei and $C$. septicum have various common antigens $[10,16,20]$ and the similarity of the $16 \mathrm{~S}$ rRNA gene sequence between $C$. chauvoei and C. septicum is $99.3 \%$ [13]. Moreover, there are problems in diagnosis, since disease caused by $C$. septicum shows very similar symptoms to blackleg. In this study, all of the $C$. chauvoei strains had the 509 bp PCR product, none of the $C$. septicum strains had a PCR product. This result suggests that the $16 \mathrm{~S}-23 \mathrm{~S}$ rDNA spacer region sequences might be less conserved than $16 \mathrm{~S}$
rRNA gene sequences between $C$. chauvoei and $C$. septicum, and that $C$. chauvoei can be distinguished from $C$. septicum by the difference in the $16 \mathrm{~S}-23 \mathrm{~S}$ rDNA spacer regions.

The isolation of $C$. chauvoei is very difficult, since $C$. chauvoei requires hard anaerobic conditions, and clinical specimens are often contaminated with other anaerobic bacteria including clostridia in soil, which grow faster than $C$. chauvoei in a culture medium. Indeed, in this study, the bacterial cells isolated from the infected muscle and blood in CLB broth did not have a 509 bp product, and the cells did not produce hemolytic zones on CLA medium (data not shown). Kuhnert et al. [14] also reported that the primary culture of samples on a blood agar plate was overgrown with the concomitantly isolated C. septicum, but gave a clear result for $C$. chauvoei in their PCR. Since blackleg is an acute infection, and most animals succumb to this disease due to acute septicemia with a high rate of mortality, rapid and direct detection systems of $C$. chauvoei without culture are desirable. Our single-step PCR system can be used as a method for identification of C. chauvoei (Table 1 and Fig. 2), and for direct detection of the bacteria in clinical materials from blackleg (Fig. 3B). Our study shows that the 16S-23S rDNA spacer regions of $C$. chauvoei have the potential to be 


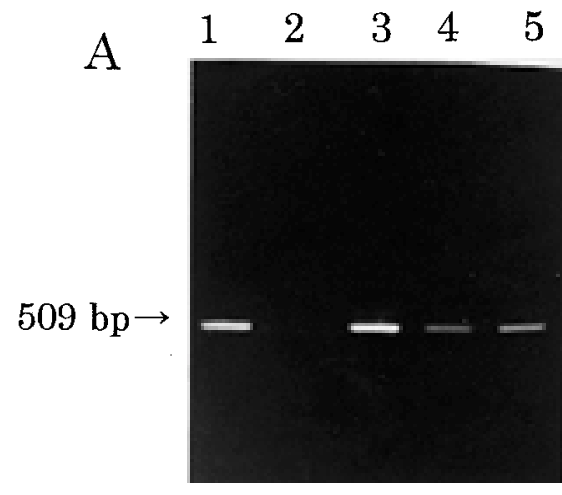

\section{$\begin{array}{llllll}1 & 2 & 3 & 4 & 5 & 6\end{array}$}

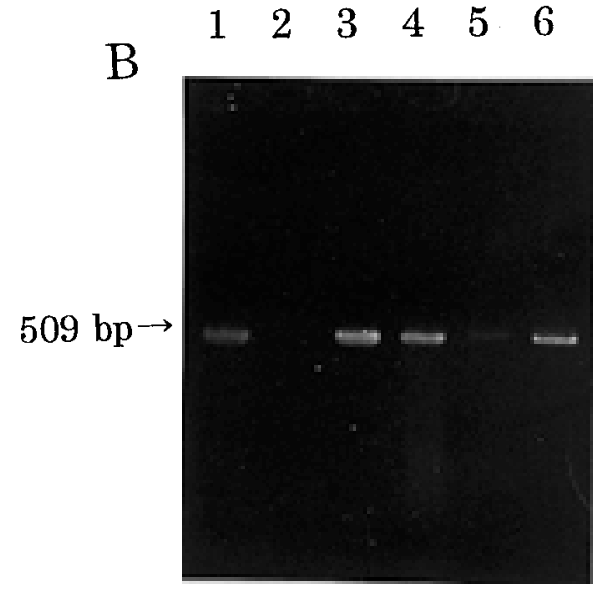

Fig. 3. (A) Detection of C. chauvoei DNA from mice experimentally infected with $C$. chauvoei by the single-step PCR system. Lane 1: culture of $C$. chauvoei ATCC10092 ${ }^{\mathrm{T}}$ (positive control), lane 2: sample from an uninfected mouse (negative control), lanes 3-5: samples from mice infected with C. chauvoei. (B) Detection of $C$. chauvoei DNA from clinical materials by the single-step PCR system. Lane 1: culture of $C$. chauvoei ATCC $10092^{\mathrm{T}}$ (positive control), lane 2: sample of muscle from an uninfected cow (negative control), lane 3: sample of blood from a cow infected with blackleg, lane 4: sample of muscle from the cow, lane 5: sample of liver from the cow, lane 6: culture of liver from the cow.

used as identification markers of $C$. chauvoei. Especially, $r r n A$ is a fundamental $16 \mathrm{~S}-23 \mathrm{~S}$ rDNA spacer region in $C$. chauvoei, which could possibly be used for determining $C$. chauvoei DNA from clinical materials.

Comparison of the $16 \mathrm{~S}-23 \mathrm{~S}$ rDNA spacer region sequences of the causative clostridia of gas gangrene, such as C. septicum, C. novyi, C. sordellii and C. perfringens, enabled the design of species-specific oligonucleotide primers for use in PCR-based detection. This single-step PCR system may serve as an improved diagnostic method for $C$. chauvoei infection based on molecular genetics.

\section{REFERENCES}

1. Appuhamy, S., Low, J.C., Parton, R. and Coote, J.G. 1998. Specific PCR primers from the 16S-23S rRNA spacer region for the rapid detection and identification of Actinobacillus seminis. J. Appl. Microbiol. 85: 941-948.

2. Azechi, H., Seto, K., Mukawa, Y. and Suzuki, K. 1962. Studies on the potency test of blackleg vaccine. Jpn. J. Vet. Sci. 24: 267-275 (in Japanese).

3. Barry, T., Colleran, G., Glennon, M., Dunican, L.K. and Gannon, F. 1991. The $16 \mathrm{~S} / 23 \mathrm{~S}$ ribosomal spacer region as a target for DNA probes to identify eubacteria. PCR Methods Appl. 1: 51-56.

4. Fuch, P. and Guillou, J.P. 1993. Detection by in vitro amplification of the alpha-toxin (phospholipase C) gene from Clostridium perfringens. J. Appl. Bacteriol. 74: 61-66.

5. Furuta, T., Kaneko, E., Suzuki, M., Arai, H. and Futami, H. 1996. Quantitative study of Helicobacter pylori in gastric mucus by competitive PCR using synthetic DNA fragments. J. Clin. Microbiol. 34: 2421-2425.

6. Garnier, T., Canard, B. and Cole, S.T. 1991. Cloning, mapping, and molecular characterization of the rRNA operons of Clostridium perfringens. J. Bacteriol. 173: 5431-5438.

7. Gurtler, V. 1993. Typing of Clostridium difficile strains by PCR-amplification of variable length $16 \mathrm{~S}-23 \mathrm{~S}$ rDNA spacer regions. J. Gen. Microbiol. 139: 3089-3097.

8. Gurtler, V. and Barrie, H.D. 1995. Typing of Staphylococcus aureus strains by PCR-amplification of variable-length 16S-23S rDNA spacer regions: characterization of spacer sequences. Microbiology 141: 1255-1265.

9. Gürtler, V. and Stanisich, V.A. 1996. New approaches typing and identification of bacteria using the 16S-23S rDNA spacer region. Microbiology 142: 3-16.

10. Hamaoka, T. and Terakado, N. 1994. Demonstration of common antigens on cell surface of Clostridium chauvoei and Clostridium septicum by indirect-immunofluorescence assay. $J$. Vet. Med. Sci. 56: 371-373.

11. Havard, H.L., Hunter, S.E.C. and Titball, R.W. 1992. Comparison of the nucleotide sequence and development of a PCR test for the epsilon toxin gene of Clostridium perfringens type $\mathrm{B}$ and type D. FEMS Microbiol. Lett. 97: 77-82.

12. Jensen, M.A., Webster, J.A. and Straus, N. 1993. Rapid identification of bacteria on the basis of polymerase chain reactionamplified ribosomal DNA spacer polymorphisms. Appl. Environ. Microbiol. 59: 945-952.

13. Kuhnert, P., Capaul, S.E., Nicolet, J. and Frey, J. 1996. Phylogenetic positions of Clostridium chauvoei and Clostridium septicum based on 16S rRNA gene sequences. Int. J. Syst. Bacteriol. 46: 1174-1176.

14. Kuhnert, P., Krampe, M., Capaul, S.E., Frey, J. and Nicolet, J. 1997. Identification of Clostridium chauvoei in cultures and clinical material from blackleg using PCR. Vet. Microbiol. 57: 291-298.

15. Morgan, E.A., Ikemura, T. and Nomura, M. 1977. Identification of spacer rRNA genes in individual ribosomal RNA transcription units of Escherichia coli. Proc. Natl. Acad. Sci. U.S.A. 74: 2710-2714.

16. Poxton, I.R. and Byrne, M.D. 1984. Demonstration of shared antigens in the genus Clostridium by an enzyme-linked immunosorbent assay. J. Med. Microbiol. 17: 171-176.

17. Takeuchi, S., Hashizume, N., Kinoshita, T., Kaidoh, T. and Tamura, Y. 1997. Detection of Clostridium septicum hemolysin gene by polymerase chain reaction. J. Vet. Med. Sci. 59: 853- 
855.

18. Vaneechoutte, M. and VanEldere, J. 1997. The possibilities and limitations of nucleic acid amplification technology in diagnostic microbiology. J. Med. Microbiol. 46: 188-194.

19. Whelen, A.C. and Persing, D.H. 1996. The role of nucleic acid amplification and detection in the clinical microbiology laboratory. Annu. Rev. Microbiol. 50: 349-373.
20. Weinberg, M. and Mihailesco, M. 1929. Recherches sur le charbon symptomatique et le B.chauvoei. Annales de I'Institut Pasteur 43: 1408-1464.

21. Yamagishi, T., Sugitani, K., Tanishima, K. and Nakamura, S. 1997. Polymerase chain reaction test for differentiation of five toxin types of Clostridium perfringens. Microbiol. Immunol. 41: 295-299. 